\title{
Biofeedback and the electromyographic activity of pelvic floor muscles in pregnant women
}

\author{
Biofeedback na atividade eletromiográfica dos músculos do assoalho \\ pélvico em gestantes
}

Roberta L. A. Batista, Maira M. Franco, Luciane M. V. Naldoni, Geraldo Duarte, Anamaria S. Oliveira, Cristine H. J. Ferreira

\begin{abstract}
Background: Maintaining continence is among the functions of the pelvic floor muscles (PFM) and their dysfunction can cause urinary incontinence (UI), which is a common occurrence during pregnancy and the puerperal period. Pelvic floor muscle training (PFMT), therefore, is important during pregnancy, although most women perform the muscle contractions unsatisfactorily. Objectives: This study is an exploratory analysis of the results of three electromyographic (EMG) activity biofeedback sessions in pregnant women. Methods: The study sample included 19 nulliparous women with low risk pregnancies. The participants performed three sessions of EMG biofeedback consisting of slow and fast contractions. The average value of the normalized amplitudes of surface electromyography was used to evaluate the results. The linear regression model with mixed effects was used for statistical analysis, with the EMG data normalized by maximum voluntary contraction (MVC). Results: A steady increase in EMG amplitude was observed during each contraction and by the end of the biofeedback sessions, although this difference was only significant when comparing the first tonic contraction of each session $(p=0.03)$. Conclusions: The results indicate that three sessions of training with biofeedback improved PFM EMG activity during the second trimester in women with low-risk pregnancies. The effectiveness of this protocol should be further investigated in randomized controlled trials.
\end{abstract}

Keywords: pelvic floor; biofeedback; electromyography; physical therapy; rehabilitation.

\section{Resumo}

Contextualização: Dentre as funções dos músculos do assoalho pélvico (MAPs), pode-se citar a manutenção da continência, sendo que sua disfunção pode causar a incontinência urinária (IU), muito frequente no período gestacional e no puerpério. Diante disso, se faz importante o treinamento dos músculos do assoalho pélvico (TMAP) durante o período gestacional, entretanto grande parte das mulheres realiza a contração dessa musculatura de maneira insatisfatória. Objetivos: Realizar uma análise exploratória dos resultados de três sessões de biofeedback na atividade eletromiográfica em mulheres gestantes. Métodos: Este estudo incluiu 19 gestantes nulíparas com gravidez de baixo risco. Foram realizadas três sessões de biofeedback eletromiográfico compostas por contrações lentas e rápidas, utilizando-se como método de avaliação dos resultados as médias das amplitudes normalizadas da eletromiografia (EMG) de superfície. Para a análise estatística, utilizou-se o modelo de regressão linear com efeitos mistos, sendo que os dados da EMG foram normalizados pela contração voluntária máxima (CVM). Resultados: Após as sessões de biofeedback, constatou-se um aumento crescente na amplitude eletromiográfica a cada contração realizada e a cada sessão, entretanto essa diferença só foi estatisticamente significante para a comparação entre a primeira contração tônica de cada sessão ( $p=0.03$ ). Conclusões: Os resultados obtidos indicam que três sessões de treinamento com biofeedback melhoraram a atividade eletromiográfica dos MAPs em gestantes de baixo risco no segundo trimestre. A efetividade do protocolo necessita ser futuramente investigada em estudo randomizado controlado.

Palavras-chave: assoalho pélvico; biofeedback; eletromiografia; fisioterapia; reabilitação.

Received: 11/20/2010 - Revised: 03/30/2011 - Accepted: 05/10/2011 


\section{Introduction $: \because$.}

During the gestational period, the pelvic floor muscles (PFM) suffer a growing weight overload imposed by the pregnant uterus. Moreover, specific hormonal alterations during this period reduce muscle tonus and strength ${ }^{1}$, predisposing pregnant woman to PFM dysfunctions such as urinary incontinence (UI), fecal incontinence (FI), pelvic organ prolapse (POP) and sexual dysfunction ${ }^{2,3}$.

The prevalence of UI during pregnancy is high, ranging from $24.3 \%$ to $63.8 \%$ in several studies ${ }^{4-8}$. In a Cochrane Library systematic review, Hay-Smith et al. ${ }^{9}$ evaluated the effects of pelvic floor muscle training (PFMT) on UI in pregnant women and concluded that women who undertook such training reported less UI during pregnancy, which supports the routine recommendation of PFMT during prenatal care.

Several studies ${ }^{10-12}$ investigating the benefits of PFMT during pregnancy have prescribed the training to women between the $20^{\text {th }}$ and $36^{\text {th }}$ week of pregnancy to allow approximately 16 weeks of training. However, the success of training depends on the ability to effectively contract $\mathrm{PFM}^{13}$. It is estimated that $30 \%$ of women are unable to contract PFM on the first attempt. Other studies have demonstrated that about 49\% do not achieve sufficient contraction to increase urethral pressure ${ }^{14}$. Another percentage do not perform the contraction in such a way as to reduce the diameter of the levator hiatus and elevate the bladder neck ${ }^{15}$.

Vaginal palpation is considered the most effective method for identifying PFM contraction capacity and should precede indirect evaluations with a perineometer or direct evaluations with a dynamometer ${ }^{16}$. The literature contains controversial results on the reliability of vaginal palpation for classifying PFM function ${ }^{17,18}$. Several scales for assessing PFM function by means of vaginal palpation are available in the literature, although the most widely used is the Modified Oxford Scale, which shows good inter-rater reliability ${ }^{18,19}$.

Electromyographic (EMG) using a vaginal sensor is an evaluation method that has recently been used to assess PFM function $^{20-24}$ and has demonstrated satisfactory results as a means of biofeedback in UI and FI treatments ${ }^{23-26}$. Nevertheless, the vast majority of studies using electromyographic biofeedback do not present normalized data ${ }^{23,24,26,27}$ although the Guide for Use and Interpretation of Kinesiologic Electromyographic Data recommends that special attention be paid to this aspect in biofeedback studies ${ }^{28}$.

Several randomized controlled trials investigating PMFT have followed clinical practice by teaching women to improve their PFM contraction performance in two or three practice sessions before beginning the 3 to 6 month training periods. The literature offers no information on the effects of a series of training sessions on EMG activity. Moreover, related studies have not normalized their data and thus their results regarding intra- and intergroup comparisons are questionable. Thus, as an exploratory study verifying the results of three biofeedback training sessions on the EMG activity of PFM in women with low-risk pregnancies, the clinical relevance of this study is thereby justified.

\section{Methods $: \because$.}

\section{Subjects and procedures}

Nineteen nulliparous pregnant women were recruited verbally to participate in the study, which was developed at the Laboratory for the Functional Evaluation of the Pelvic Floor (LAFAP) of the Clinical Hospital, Ribeirão Preto School of Medicine of the Universidade de São Paulo (HC-FMRP/USP), Ribeirão Preto, SP, Brazil. All pregnant women received prenatal care at public health clinics in greater Ribeirão Preto and agreed to participate in the study by signing the informed consent form. Pregnant women over 18 years old between $18^{\text {th }}$ and $19^{\text {th }}$ week of low-risk, single-fetus topical pregnancies were included in the study. Exclusion criteria consisted of missing one of the three biofeedback sessions or discomfort using the vaginal probe. This study was approved by the Ethics in Research Committee of HC-FMRP/USP (protocol n 9528/2006).

All volunteers participated in three sessions that occurred once a week. In the first week, orientation regarding the location and function of the PFM was given and then the participant's PFM were evaluated by means of bidigital palpation of the vagina to verify the contraction capacity and the degree of muscle function on the Modified Oxford Scale.

Rating is subjective on the Oxford Scale and considers two aspects of PFM contraction: compression and elevation. Elevation is present only in "moderate", "good" and "strong" contractions. Thus, grade 0 represents absence of contraction; grade 1 represents the beginnings of a contraction, i.e., the examiner perceives a pulsing sensation; grade 2 is a weak contraction, i.e., with the presence of mild compression; in grade 3 there is moderate compression and the examiner senses the elevation of the fingers; grade 4 is a good contraction with significant elevation of the examiner's fingers; a grade 5 contraction includes strong compression associated with elevation of the examiner's fingers ${ }^{29}$. All evaluations were carried out by the same examiner, who has 5 years of experience with PFM evaluation.

Next, preparations for EMG were begun, including positioning the active electrode (intravaginal sensor), which was surrounded by a spoonful of water-based gel and inserted in the vaginal opening, remaining entirely within the cavity. The 
reference electrode was placed on the pubic symphysis. As the EMG signal came online, the volunteer's attention was directed to the computer monitor (biofeedback). Ten voluntary contractions were performed and maintained for 6 seconds, with 6 seconds between each. This procedure was designed to familiarize the participants with the equipment and the PFM contraction in such a way as to be able to isolate it, as well as for us to obtain values for signal normalization ${ }^{30}$.

A new probe was assigned to each participant; after each use it was washed with soap and water, dried with a paper towel, and stored in a plastic bag with the volunteer's name for use the following week.

The signal from the PFM electrical activity was transmitted with a Thought Technology Ltd. ${ }^{\circledR}$ vaginal sensor (model AS 9572). The receiver's surface is stainless steel; it is $27 \mathrm{~mm}$ in diameter and $69 \mathrm{~mm}$ in length, features an input impedance of $1010 \mathrm{G} \Omega^{12}$, a frequency band of $10-1 \mathrm{KHz}$ and a common mode rejection ratio $(\mathrm{CMRR})>130 \mathrm{~dB}$. For EMG signal capture, a surface EMG system (MyoTrac Infinit) was used with an acquisition frequency of $1 \mathrm{KHz}$ and an accuracy gain of $0.5 \%$ was used.

The EMG recording included three 2-second maximum voluntary contractions (MVC) with 2 seconds between each by each volunteer. These voluntary contractions were used for the subsequent normalization of the EMG data ${ }^{31}$.

One week after this procedure, the volunteers returned to the lab to have their PFM function rated (as described above) on the Modified Oxford Scale. Their EMG activity was then recorded according to the following protocol: two slow contractions were maintained for 6 seconds, with 6 seconds between each contraction; after resting for 60 seconds, two fast contractions were maintained for 2 seconds, with 2 seconds between each. The following week, all volunteers returned to carry out the same procedures. All volunteers performed the same number of contractions in each session. There was no need for extra repetitions to correct the muscle contraction, which was possibly due to the previous learning session.

The evaluations were carried out with the pregnant women in supine position, with flexion and abduction of the hip joint and all sessions were conducted by the same examiner.

During each contraction, the abdomen and PFM of the pregnant woman were observed to identify if the Valsalva maneuver was performed and if the hip adductor muscles and gluteus muscles were being simultaneously contracted, instead of the isolated contraction of PFM. In case of accessory muscle contraction, the PFM contraction was to be disregarded, although this did not occur at any point. These steps were taken to avoid surface EMG cross-talk ${ }^{32-34}$.

The EMG signal was band-pass analog filtered from 20 to $500 \mathrm{~Hz}$ and then log- transformed into Root Mean Square
(RMS). From the RMS value of the signal, its mean value was determined during the rest period and contractions. For analysis purposes, the first second of each contraction was excluded.

Several references can be used for normalization, although the most common is to use the maximum or mean value of two to three $\mathrm{MVCs}^{35}$.

In this study, the RMS values were normalized using the maximum value of the EMG amplitude obtained in one of the three MVCs, i.e., by the ratio between the mean value of the amplitude obtained in the evaluated activity and the maximum MVC value.

All means and the standard deviation were normalized and then the difference between the contraction mean and the rest mean (baseline) was calculated using these data.

Statistical analysis was carried out using SAS v9.0 for descriptive measures, and the graphs were built using $\mathrm{R}$ software. Initially, an exploratory analysis of the data was carried out in an attempt to synthesize values of the same nature to get a more complete picture of them.

The linear regression model with mixed effects (random and fixed effects) was used to reach the aims proposed in this study. This mixed model estimates the two components of variability present in this study: intra- and intersubject, considering biological variability, measurement or calculation errors as well as differences between individuals. P values $<0.05$ were considered significant.

\section{Results $: \because$.}

The participants' mean age was $24.05 \pm 6.22$ years, with a body mass index (BMI) of 24.06 at the 18th week of gestation. No volunteer had a history of previous gynecological surgery. Regarding the presence of urine loss in the four weeks prior to the trials, most of volunteers (63.16\%) reported none under any conditions. Most of women were white $(63.16 \%)$ and $78.95 \%$ had completed high school.

The following classifications of volunteer PFM function were determined according to the Modified Oxford Scale: grade $2=57.89 \%$ (11) of the volunteers, grade $3=26.32 \%$ (5), grade $4=10.53 \%$ (2) and grade $5=5.26 \%$ (1).

\section{Intra- and intersession PFM contraction behavior with EMG biofeedback}

Analysis of the mean contractions evaluated using EMG showed that the amplitude increased with each contraction and each session, i.e., an improvement in EMG activity. This suggests muscle function was improved with each contraction 


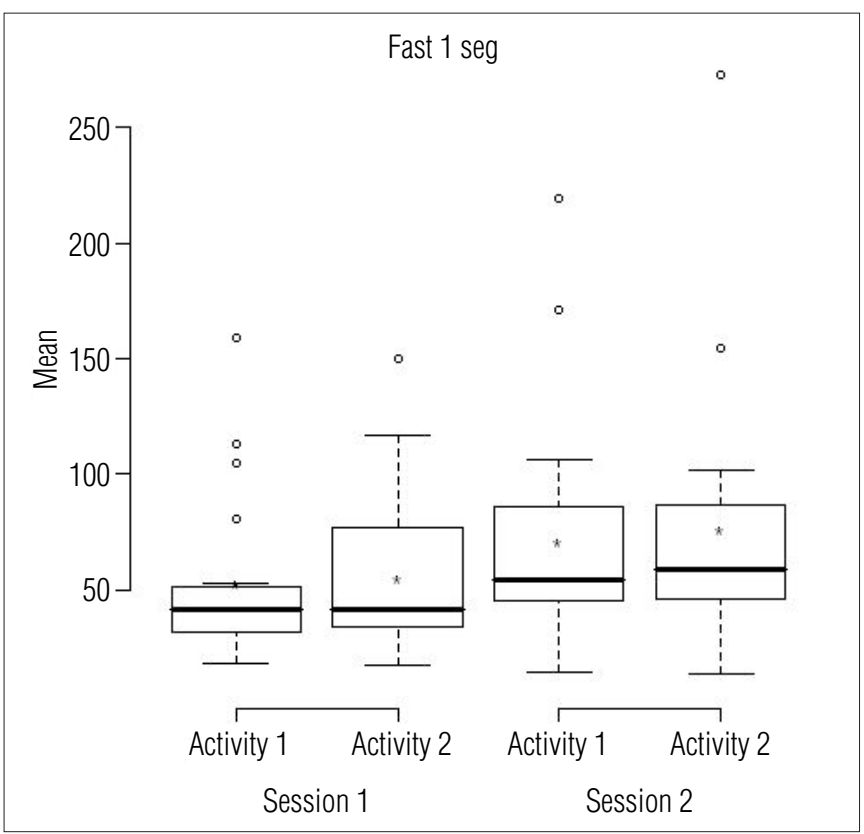

Figure 1. Mean electromyographic activity of fast contractions inter and intra-sessions $n=19$.

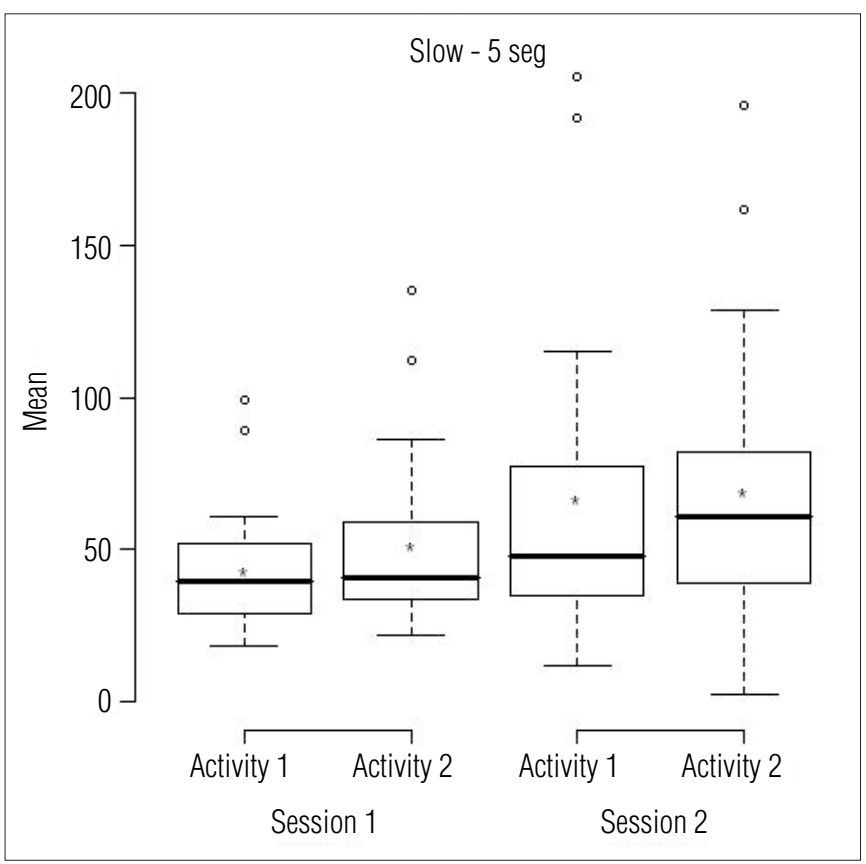

Figure 2. Mean electromyographic activity of slow contractions inter and intra-sessions $n=19$.

performed (Figures 1 and 2). However, the EMG activity increase did not only increase during the contractions, but also during the rest period at the beginning of session, although nonsignificantly ( $\mathrm{p}=0.54)$ (Figure 3$)$.

Although the EMG amplitudes increased, these differences were not significant, except when comparing the first slow contraction performed in the first session with the first slow contraction performed in the second session $(p=0.03)$,

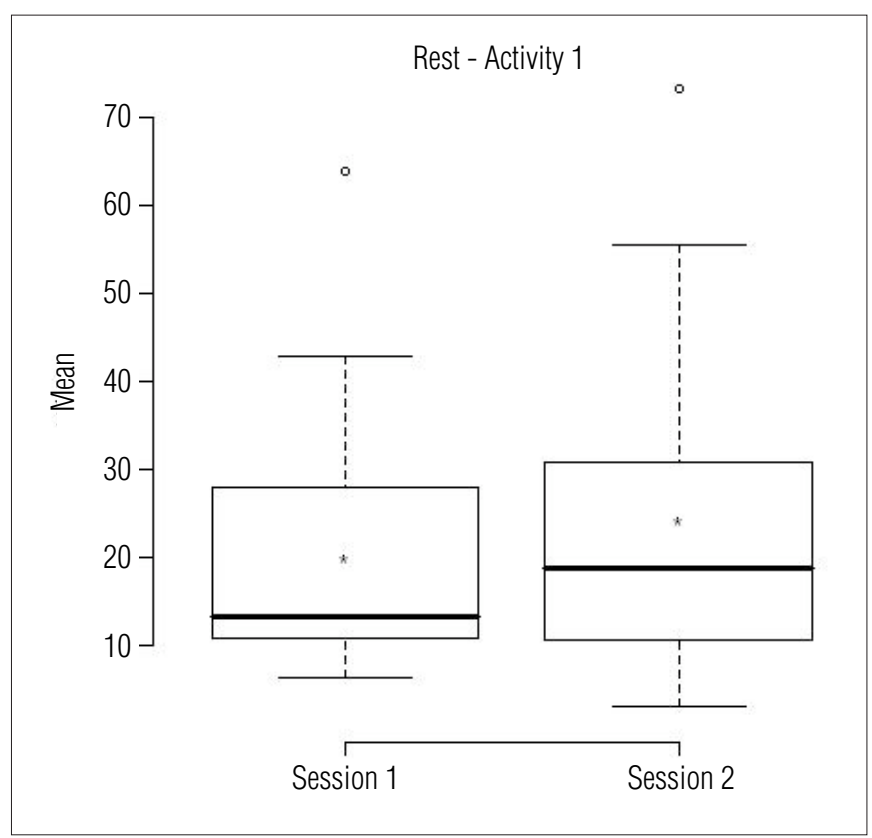

Figure 3. Mean electromyographic activity of rest inter and intrasessions $n=19$.

as well as the difference between the second fast contraction between sessions, which almost fell within the significance range ( $\mathrm{p}=0.06)$. These data are available in Table 1; the real values obtained in each contraction and rest interval are demonstrated in Table 2.

\section{Discussion $: \because$.}

The presence of PFM dysfunction (mainly UI) during pregnancy and puerperium is well-known, with a prevalence ranging between $24.3 \%$ and $63.8 \%$ during pregnancy ${ }^{48}$. Due to this high prevalence, it is necessary to evaluate PFM contraction capacity in order to institute a training program that can treat such dysfunctions by improved muscle function. Several studies have verified the positive influence of PFM during pregnancy and puerperium for reducing $\mathrm{UI}^{5,10}$.

This study aimed to verify the effectiveness of three EMG biofeedback sessions for improving PFM activity in pregnant women. The purpose of the PFM training program was to promote correct and effective contractions, i.e., to perform a caudal movement without expulsion force or contracting accessory muscles such as the abdominals, gluteals or adductors ${ }^{14}$.

Three exercise sessions with biofeedback improved EMG activity, suggesting better muscle function. Although increased muscle function can be attributed to the fact that muscle hypertrophy occurs from exercising two or three times a week for three months ${ }^{36}$, the improvement may also be associated with neuromuscular adaptations, such as 
Table 1. Comparisons inter and intra-sessions.

\begin{tabular}{lcccc}
\hline \multirow{2}{*}{ Comparison } & Estimated difference & P-value & \multicolumn{2}{c}{$95 \% \mathrm{Cl}$ for the difference } \\
& & & $\mathrm{LI}$ & $\mathrm{LS}$ \\
\hline Session 1 (Fast/ contraction 1- Fast/ contractios 2) & -0.14 & 0.82 & -1.34 & 1.06 \\
\hline Session 2 (Fast / contraction 1- Fast/ contraction 2) & -0.28 & 0.65 & -1.47 & 0.92 \\
\hline Session 1 (Slow/ contraction 1- Slow/ contraction 2) & -0.52 & 0.39 & -1.72 & 0.68 \\
\hline Session 2 (Slow / contraction 1 - Slow / contraction 2) & -0.13 & 0.83 & -1.33 & 1.07 \\
\hline Rest (Session 1 - Session 2) & -0.37 & 0.54 & -1.57 & 0.82 \\
\hline Fast / contraction 1 (Session 1- Session 2) & -1.03 & 0.09 & -2.23 & 0.17 \\
\hline Fast/ contraction 2 (Session 1- Session 2) & -1.17 & 0.06 & -2.37 & 0.03 \\
\hline Slow / contraction 1 (Session1- Session 2) & -1.31 & 0.03 & -2.51 & -0.11 \\
\hline Slow / contraction 2 (Session 1- Session 2) & -0.92 & 0.13 & -2.12 & 0.28 \\
\hline
\end{tabular}

Table 2. Values obtained with each contraction and rest in each session.

\begin{tabular}{lllllccc}
\hline Group & Sesssion & $\mathrm{n}$ & Mean & SD & Minimum & Median & Maximum \\
\hline \multirow{2}{*}{ Slow 5 seg - Contraction 1 } & Sesssion 1 & 19 & 43.23 & 22 & 18.15 & 39.87 & 99.17 \\
\cline { 2 - 8 } & Sesssion 2 & 19 & 67.02 & 52.72 & 11.88 & 48.09 & 205.47 \\
\hline \multirow{2}{*}{ Slow 5 seg - Contraction 2 } & Sesssion 1 & 19 & 51.14 & 30.47 & 21.94 & 40.57 & 135.07 \\
\cline { 2 - 8 } & Sesssion 2 & 19 & 69.31 & 48.4 & 2.23 & 60.76 & 195.7 \\
\multirow{2}{*}{ Rest } & Sesssion 1 & 19 & 19.99 & 15.1 & 6.3 & 13.23 & 63.83 \\
\cline { 2 - 8 } \multirow{2}{*}{ Fast 1 seg - Contraction 1 } & Sesssion 2 & 19 & 24.28 & 19.11 & 3.07 & 18.83 & 73.31 \\
\hline \multirow{2}{*}{ Fast 1 seg - Contraction 2 } & Sesssion 1 & 19 & 53.16 & 36.12 & 18.11 & 41.5 & 158.89 \\
\cline { 2 - 8 } & Sesssion 2 & 19 & 70.96 & 50.21 & 14.55 & 54.65 & 219.54 \\
\hline
\end{tabular}

neural activation ${ }^{37}$. According to Remple et al. ${ }^{38}$, neural adaptations would explain increases in muscle function before hypertrophy could occur. This effect is related to motor learning, since the more motor units that are recruited, the better will be muscle function.

The present study verified that three weeks of weekly PFM training sessions promoted increased EMG activity, which may have been due to improved contraction perception. Nevertheless, it cannot be confirmed that this was due to the use of EMG biofeedback. Similar results could perhaps be obtained using only vaginal palpation as a contraction stimulus.

Aiming at to evaluate the effects of PFMT in nulliparous pregnant women, Oliveira et al. ${ }^{12}$ carried out a study that included 46 pregnant women divided into two groups: controls and subjects who underwent PFMT for 12 weeks. Bidigital vaginal palpation with Ortiz Scale for classification, and perineometry with and without biofeedback were used to analyze the results. These authors observed a significant increase in muscle function using palpation and perineometry in both the PFMT and control groups. They suggested that the increase in the control group was due to the PFM perception that the women gained through the evaluation. However, they observed higher values in the perineometer evaluation with biofeedback than without it, suggesting that visual stimulation facilitates PFM perception and increased muscle function.
Several studies have tested the effectiveness of UI or FI treatment involving biofeedback and have observed satisfactory results ${ }^{24-26}$. PFMT associated with biofeedback provides equally good results for reducing UI symptoms and improving muscle function. Dannecker et al. ${ }^{23}$ reported a significantly increased scores using vaginal palpation in conjunction with the Oxford Scale $(\mathrm{p}<0.001)$ after a mean of 8.7 sessions with EMG biofeedback in a sample of 163 patients. They also found a significant increase in EMG activity $(\mathrm{p}=0.001)$ and observed UI improvements using a urodynamic exam and questionnaire.

After six and 12 sessions of PFMT with EMG biofeedback, Rett et al. ${ }^{24}$ observed increased EMG amplitudes and improved function using bidigital vaginal palpation, the Brink Scale and perineometry. They found that EMG amplitudes were higher in fast contractions and lower in contractions of 10 and $20 \mathrm{sec}-$ onds, respectively. The present study also reported a greater increase in EMG activity in the fast contractions, possibly due to the nature of type II muscle fibers, which can produce greater strength and power, but are easily fatigued ${ }^{13}$.

There are few studies reporting on the EMG values in PFM evaluations, which impedes the establishment of normality parameters. Capelini et al. ${ }^{26}$ report a progressive increase in EMG activity, although they do not show the obtained values, since the numbers were not significant due to the number of variables, which according to the authors may affect 
comparisons. However, with the data normalization procedure, as was carried out in the present study, the interference that EMG amplitude may suffer due to tissue thickness and subcutaneous resistance, vaginal impedance and electrode positioning was minimized. Thus, the results of the present study can be thus compared ${ }^{33}$.

Although our results can be compared with other studies involving the EMG activity of the PFM, such comparisons are hindered, since most of them either did not carry it out or did not describe the procedure, as in the study of Aukee, Penttinen and Airaksinen ${ }^{27}$. In this study, the authors compared the EMG activity of the PFM in asymptomatic women and with women suffering from UI. The mean of three contractions in the supine and standing position was analyzed and resulted in the following values: muscle activity in the supine position was $19.5 \mu \mathrm{V}$ and $17.0 \mu \mathrm{V}$ in the control group and UI group, respectively; activity in the standing position was $18.2 \mu \mathrm{V}$ for the control group and $12.9 \mu \mathrm{V}$ for the UI group. In the present study, the mean values of EMG amplitudes during contractions ranged between $43.23 \mu \mathrm{V}$ and $76.3 \mu \mathrm{V}$ and during rest ranged between $19.99 \mu \mathrm{V}$ and $24.28 \mu \mathrm{V}$, which are higher than those observed by Aukee, Penttinen and Airaksinen ${ }^{27}$. However these authors either did not carry out or did not describe the data normalization procedure, which prohibits comparison that could justify the differences.

EMG biofeedback can teach contraction procedure, resulting in increased EMG activity and improved muscle function, which suggests that more effective contractions were performed and that it can make PFMT programs more effective. This suggests that a few sessions of PFMT training may improve EMG activity and may be an important step towards greater effectiveness in longer training programs for muscle strength gains.

Furthermore, incontinent women who can appropriately contract the PFM may reduce stress incontinence before completing the muscle strength training program simply by triggering the PFM in moments of increased intra-abdominal pressure $^{39}$. This could mean that short-term training in the second trimester that emphasizes increased muscle activity may quickly improve stress incontinence. Such training should not be seen as a substitute for more extensive PFMT, which is widely recommended according to a Cochrane systematic review ${ }^{40}$. Future studies should evaluate the effectiveness of three biofeedback sessions for boosting the PFMT protocol regarding improved muscle function and decreased UI and stress incontinence in the short and long term.

The main limitations of this study are the absence of a control group and the small sample size, which indicates the need to carry out randomized controlled trials to verify the results of this exploratory study. To our knowledge this is the first study to investigate the impact of a few training sessions with biofeedback on PFM EMG activity in pregnant women. Its main contribution is the possibility that PFMT effects during pregnancy may be augmented by learning to perform effective contractions in three biofeedback sessions.

\section{Conclusion $: \because$.}

This study involving women in the second trimester of pregnancy verified that three sessions of EMG biofeedback led to increased EMG activity, suggesting that visual stimulation may help PFM contraction performance. However, more studies should be carried out to verify the number of biofeedback sessions necessary to improve contraction performance. These studies must normalize their data to allow reliable comparisons of their results. It should also be stressed that such studies should involve pregnant women due to the prevalence of UI in pregnancy and the recommendations for PFMT during this period.

\section{Acknowledgments $: \because$}

To the Fundação de Amparo a Pesquisa do Estado de São Paulo (FAPESP) - protocol 07/50824-9.

\section{References}

1. Wijma J, Weis Potters AE, Wolf BT, Tinga DJ, Aarnoudse JG. Anatomical and functional changes in the lower urinary tract during pregnancy. BJOG. 2001;108(7):726-32.

2. Bump R, Norton PA. Epidemiology and natural history of pelvic floor dysfunction. Obstet Gynecol Clin North Am. 1998;25(4):723-46.

3. Devreese A, Staes F, De Weerdt W, Feys H, Van Assche A, Penninckx F, et al. Clinical evaluation of pelvic floor muscle function in continent and incontinent women. Neurourol Urodyn. 2004;23(3):190-7.

4. Bø K, Haakstad L, Voldner N. Do pregnant women exercise their pelvic floor muscles? Int Urogynecol J Pelvic Floor Dysfunct. 2007;18(7):733-6.
5. Dinc A, Kizilkaya Beji N, Yalcin 0. Effect of pelvic floor muscle exercises in the treatment of urinary incontinence during pregnancy and the postpartum period. Int Urogynecol J Pelvic Floor Dysfunct. 2009;20(10):1223-31.

6. Kocaöz S, Talas MS, Atabekoğlu CS. Urinary incontinence in pregnant women and their quality of life. J Clin Nurs. 2010;19(23-24):3314-23.

7. Martins G, Soler ZA, Cordeiro JA, Amaro JL, Moore KN. Prevalence and risk factors for urinary incontinence in healthy pregnant Brazilian women. Int Urogynecol J Pelvic Floor Dysfunct. 2010;21(10):1271-7.

8. Solans-Domènech M, Sanchez E, Espuña-Pons M; Pelvic Floor Research Group (Grup de 
Recerca del Sòl Pelvià; GRESP). Urinary and anal incontinence during pregnancy and postpartum: incidence, severity, and risk factors. Obstet Gynecol. 2010;115(3):618-28.

9. Hay-Smith J, Mørkved S, Fairbrother KA, Herbison GP. Pelvic floor muscle training for prevention and treatment of urinary and faecal incontinence in antenatal and postnatal women. Cochrane Database of Systematic Reviews. In: The Cochrane Library, Issue 10, 2010.

10. Mørkved S, Bø K, Schei B, Salvesen KA. Pelvic floor muscle training during pregnancy to prevent urinary incontinence: a single-blind randomized controlled trial. Obstet Gynecol. 2003;101(2):313-9.

11. Salvesen KA, Mørkved S. Randomised controlled trial of pelvic floor muscle training during pregnancy. BMJ. 2004;329(7462):378-80.

12. Oliveira C, Lopes MAB, Pereira LCL, Zugaib M. Effects of pelvic floor muscle training during pregnancy. Clinics. 2007;62(4):439-46.

13. Johnson VY. How the principles of exercise physiology influence pelvic floor muscle training. J Wound Ostomy Continence Nurs. 2001;28(3):150-5.

14. Bump R, Hurt WG, Fantl JA, Wyman JF. Assessment of Kegel pelvic muscle exercise performance after brief verbal instruction. Am J Obstet Gynecol. 1991;165(2):322-9.

15. Dietz HP, Shek C, Clarke B. Biometry of the pubovisceral muscle and levator hiatus by threedimensional pelvic floor ultrasound. Ultrasound Obstet Gynecol. 2005;25(6):580-5.

16. Bø K, Sherburn M. Evaluation of female pelvic-floor muscle function and strength. Phys Ther. 2005;85(3):269-82.

17. Bø K, Finckenhagen HB. Vaginal palpation of pelvic floor muscle strength: inter-test reproducibility and comparison between palpation and vaginal squeeze pressure. Acta Obstet Gynecol Scand. 2001;80(10):883-7.

18. Frawley HC. Pelvic floor muscle strength testing. Aust J Physiother. 2006;52(4):307.

19. Frawley HC, Galea MP, Phillips BA, Sherburn M, Bø K. Reliability of pelvic floor muscle strength assessment using different test positions and tools. Neurourol Urodyn. 2006;25(3):236-42.

20. Aukee P, Immonen P, Penttinen J, Laippala P, Airaksinen 0 . Increase in pelvic floor muscle activity after 12 weeks' training: a randomized prospective pilot study. Urology. 2002;60(6):1020-4.

21. Coffey SW, Wilder E, Majsak MJ, Stolove R, Quinn L. The effects of a progressive exercise program with surface electromyographic biofeedback on an adult with fecal incontinence. Phys Ther. 2002;82(8):798-811.

22. Neumann P, Gill V. Pelvic floor and abdominal muscle interaction: EMG activity and intraabdominal pressure. Int Urogynecol J Pelvic Floor Dysfunct. 2002;13(2):125-32.

23. Dannecker $\mathrm{C}$, Wolf $\mathrm{V}$, Raab R, Hepp H, Anthuber C. EMG-biofeedback assisted pelvic floor muscle training is an effective therapy of stress urinary or mixed incontinence: a 7-year experience with 390 patients. Arch Gynecol Obstet. 2005;273(2):93-7.

24. Rett MT, Simoes JA, Herrmann V, Pinto CL, Marques AA, Morais SS. Management of stress urinary incontinence with surface electromyography-assisted biofeedback in women of reproductive age. Phys Ther. 2007;87(2):136-42
25. Berghmans LC, Frederiks CM, de Bie RA, Weil EH, Smeets LW, van Waalwijk van Doorn ES, et al Efficacy of biofeedback, when included with pelvic floor muscle exercise treatment, for genuine stress incontinence. Neurourol Urodyn. 1996;15(1):37-52.

26. Capelini MV, Riccetto CL, Dambros M, Tamanini JT, Herrmann V, Muller V. Pelvic floor exercises with biofeedback for stress urinary incontinence. Int Braz J Urol. 2006;32(4):462-9.

27. Aukee P, Penttinen J, Airaksinen 0 . The effect of aging on the electromyographic activity of pelvic floor muscles. A comparative study among stress incontinent patients and asymptomatic women. Maturitas. 2003;44(4):253-7.

28. Soderberg GL, Knutson LM. A guide for use and interpretation of kinesiologic electromyographic data. Phys Ther. 2000;80(5):485-98.

29. Thyer I, Shek C, Dietz HP. New imaging method for assessing pelvic floor biomechanics. Ultrasound Obstet Gynecol. 2008;31(2):201-5.

30. Merletti R. Standards for Reporting EMG Data. J Electromyogr Kinesiology. 1999;9(1)iii-iv

31. Ervilha UF, Duarte M, Amadio AC. Estudos sobre procedimentos de normalização do sinal eletromiográfico durante o movimento humano. Rev Bras Fisioter. 1998;3(1):15-20.

32. van Veen BK, Mast E, Busschers R, Verloop AJ, Wallinga W, Rutten WLC, et al. Single fibre action potentials in skeletal muscle related to recording distances. J Electromyogr Kinesiol. 1994;4(1):37-46.

33. De Luca CJ. The use of surface electromyography in biomechanics. J Appl Biomech. 1997;13(2):135-63

34. Mathur S, Eng JJ, MacIntyre DL. Reliability of surface EMG during sustained contractions of the quadriceps. J Electromyogr Kinesiol. 2005;15(1):102-10.

35. Pincivero DM, Green RC, Mark JD, Campy RM. Gender and muscle differences in EMG amplitude and median frequency, and variability during maximal voluntary contractions of the quadriceps femoris. J Electromyogr Kinesiol. 2000;10(3):189-96.

36. Guyton AC, Hall JE. Contração músculo-esquelética. In: Guyton AC, Hall JE. Fisiologia médica. $g^{a}$ ed. Rio de Janeiro: Guanabara Koogan; 1999. p. 75.

37. Moritani T. Neuromuscular adaptations during the acquisition of muscle strength, power and motor tasks. J Biomech. 1993;26 Suppl1:95-107.

38. Remple MS, Bruneau RM, VandenBerg PM, Goertzen C, Kleim JA. Sensitivity of cortical movement representations to motor experience: evidence that skill learning but not strength training induces cortical reorganization. Behav Brain Res. 2001;123(2):133-41.

39. Burgio KL, Goode PS, Locher JL, Umlauf MG, Roth DL, Richter HE, et al. Behavioral training with and without biofeedback in the treatment of urge incontinence in older women: a randomized controlled trial. JAMA. 2002;288(18):2293-9.

40. Hay-Smith J, Bø Ki, Berghmans B, Hendriks E, de Bie R, van Waalwijk van Doorn E. Pelvic floor muscle training for urinary incontinence in women. Cochrane Database of Systematic Reviews. In: The Cochrane Library, Issue 7, 2010. 